\title{
Ambient particulate pollution and the world-wide prevalence of asthma, rhinoconjunctivitis and eczema in children: Phase One of the International Study of Asthma and Allergies in Childhood (ISAAC)
}

\author{
H Ross Anderson, ${ }^{1}$ Ruth Ruggles, ${ }^{1}$ Kiran D Pandey, ${ }^{2}$ Venediktos Kapetanakis, ${ }^{1}$ \\ Bert Brunekreef, ${ }^{3}$ Christopher K W Lai, ${ }^{4}$ David P Strachan, ${ }^{1}$ Stephan K Weiland, ${ }^{5}$ \\ the ISAAC Phase One Study Group
}

\begin{abstract}
- See Commentary, p 290
1 Division of Community Health Sciences, MRC-HPA Centre for Environment and Health, St George's, University of London, London, UK

2Environment Department, World Bank, Washington, DC, USA

${ }^{3}$ Institute for Risk Assessment Sciences, Utrecht University, Utrecht, the Netherlands and the Julius Center for Health Sciences and Primary Care, University Medical Center, Utrecht, the Netherlands ${ }^{4}$ Department of Medicine and Therapeutics, The Chinese University of Hong Kong, Hong Kong, SAR China

${ }^{5}$ Department of Epidemiology, University of Ulm, Ulm, Germany
\end{abstract}

\section{Correspondence to}

Professor H R Anderson,

Division of Community Health

Sciences, MRC-HPA Centre for Environment and Health, St George's, University of London, Cranmer Terrace, London SW17 ORE, UK;

r.anderson@sgul.ac.uk

Stephan K Weiland died on 19 March 2007.

Members of the ISAAC Phase One Study Group are listed in appendix 1

Accepted 16 August 2009

\section{ABSTRACT}

Objectives To investigate the effect of ambient particulate matter on variation in childhood prevalence of asthma, rhinoconjunctivitis and eczema.

Methods Prevalences of asthma, rhinoconjunctivitis and eczema obtained in Phase One of the International Study of Asthma and Allergies in Childhood (ISAAC) were matched with city-level estimates of residential $\mathrm{PM}_{10}$ obtained from a World Bank model. Associations were investigated using binomial regression adjusting for GNP per capita and for clustering within country. For countries with more than one centre, a two stage meta-analysis was carried out. The results were compared with a meta-analysis of published multi-centre studies. Results Annual concentrations of $\mathrm{PM}_{10}$ at city level were obtained for 105 ISAAC centres in 51 countries. After controlling for GNP per capita, there was a weak negative association between $\mathrm{PM}_{10}$ and various outcomes. For severe wheeze in 13-14-year-olds, the OR for a $10 \mu \mathrm{g} / \mathrm{m}^{3}$ increase in $\mathrm{PM}_{10}$ was $0.92195 \% \mathrm{Cl}$ 0.84 to 1.00). In 24 countries with more than one centre, most summary estimates for within-country associations were weakly positive. For severe wheeze in 13-14-yearolds, the summary OR for a $10 \mu \mathrm{g} / \mathrm{m}^{3}$ increase in $\mathrm{PM}_{10}$ was 1.01 (0.92 to 1.10). This result was close to a summary $\mathrm{OR}$ of 0.99 (0.91 to 1.06) obtained from published multi-centre studies.

Conclusions Modelled estimates of particulate matter at city level are imprecise and incomplete estimates of personal exposure to ambient air pollutants.

Nevertheless, our results together with those of previous multi-centre studies, suggest that urban background $\mathrm{PM}_{10}$ has little or no association with the prevalence of childhood asthma, rhinoconjunctivitis or eczema either within or between countries.

\section{INTRODUCTION}

Childhood asthma is a major cause of illness and disability in childhood. ${ }^{1}$ It shows large variations in occurrence world-wide and over time, ${ }^{2}{ }^{3}$ but the reasons for these variations and trends are largely unknown. Asthma is a condition characterised by inflammation and hyper-responsiveness of the airways, and those with asthma frequently report that air pollution aggravates or precipitates their asthma. It is therefore not surprising that ambient air pollution is widely believed to be one possible cause of variations in prevalence through effects on

\section{What this paper adds}

- The reasons for the wide international variations in the prevalence of childhood asthma, rhinoconjunctivitis and eczema are not understood.

- One factor might be exposure to ambient particulate matter since this has been associated with exacerbations of asthma and may also play a role in the increased prevalence of asthma symptoms and allergy observed in some traffic-proximity studies.

- In a study of over half a million children from 105 cities in 51 countries, we found little or no evidence of associations with modelled citylevel residential $\mathrm{PM}_{10}$

- The results suggest that community levels of ambient particulate matter are unlikely to explain international variations in prevalence.

- Future investigations of this topic should employ improved exposure assessment and control for confounding factors at the individual level.

incidence, severity or prognosis. The particulate component of air pollution is widely measured as particulate matter with aerodynamic diameter less than $10 \mu \mathrm{m}\left(\mathrm{PM}_{10}\right)$, this being small enough to penetrate the intrathoracic respiratory tract. $\mathrm{PM}_{10}$ is a complex mixture arising from different sources with a range of physicochemical characteristics. While some components of $\mathrm{PM}_{10}$ are likely to be more toxic than others, these differences have been difficult to quantify. ${ }^{45}$ Experimental evidence based on acute exposures suggests that particulate matter has the potential to increase airway reactivity, increase inflammatory responses in the lung and enhance allergic immune responses, ${ }^{6} 7$ but studies at environmental concentrations have been equivocal. ${ }^{8}$ Various reviews have concluded that while there is evidence that short-term increases in $\mathrm{PM}_{10}$ may aggravate symptoms of asthma, the evidence for effects of chronic exposure to $\mathrm{PM}_{10}$ on asthma incidence and prevalence is weak. ${ }^{9-11}$ There is some evidence from birth cohort studies linking traffic exposure to atopic sensitisation. ${ }^{12-14}$

The evidence for effects on asthma of chronic exposure to particulate matter may be divided into those studies which have investigated the effects of 
proximity to sources of traffic pollution and those which have investigated the effects of community-level concentrations of specific pollutants measured by urban background monitoring stations representing the residential environment. The contribution of traffic pollution to urban background concentrations varies. Traffic-proximity studies are usually conducted within a single urban area and tend to find that children living in close proximity to traffic have an increased risk of respiratory symptoms, including those of asthma, relative to those living further away. ${ }^{15} 16$ The effects of community-level exposure on prevalence are usually investigated by comparing urban areas using urban background concentrations of pollutants; these studies tend to find associations with bronchitic type symptoms rather than with asthma or allergic symptoms, but interpretation is frequently hampered by the small number of areas compared, often as low as two, and by the ecological nature of such studies. We identified nine studies of children comparing five or more centres and none found evidence of a statistically significant positive association between ambient particulate matter and asthma symptoms. ${ }^{17-25}$ This is unlikely to be entirely explained by exposure measurement error because the same studies often report other adverse effects, including bronchitic symptoms in those with and without asthma, reductions in lung function and increased mortality rates in adults.

Current evidence therefore suggests that despite associations between asthma prevalence and proximity to traffic, and between asthma exacerbations and short-term variations in air pollution measured at community monitors, particulate matter does not play a role in determining asthma prevalence in a population. Current evidence is, however, based on comparisons of a limited number of cities or communities within individual developed countries. The exception is a study of nitrogen dioxide and asthma prevalence in 62 centres in five largely European countries. ${ }^{26}$ There are no published international studies of city-level average concentrations of background particulate matter and asthma prevalence. The role of particulate matter in determining variations in asthma prevalence world-wide has not been investigated.

Phase One of the International Study of Asthma and Allergies in Childhood (ISAAC) study published prevalence estimates for symptoms and diagnoses of asthma, rhinoconjunctivitis and eczema from 6-7-year-old children in 91 centres in 38 countries and from 13-14-year-old children in 156 centres in 56 countries. ${ }^{27}$ Measures of ambient air pollution in ISAAC centres are sparse. However, model estimates of annual concentrations of ambient particle concentrations $\left(\mathrm{PM}_{10}\right)$ in residential areas of all cities with a population of more than 100000 are available from a model developed at the World Bank. ${ }^{28}$ These had been used by WHO to estimate the global impact of particulate matter on mortality. This provided an opportunity to investigate the association between city-level estimates of residential exposure to urban background $\mathrm{PM}_{10}$ and the prevalence of asthma, rhinoconjunctivitis and eczema in children in a large number of cities world-wide.

\section{METHODS}

The ISAAC protocol and results for the prevalence of symptoms of asthma, rhinoconjunctivitis and eczema have been published. ${ }^{27}{ }^{29}$ Briefly, each centre obtained data on 13-14-yearold children from a self-completed questionnaire at school. Optionally, data on 6-7-year-old children were obtained using parent-completed questionnaires. The schools were selected to represent a defined geographical area with a target sample of 3000 children per centre per age group.
The International Data Centre in Auckland supplied the raw survey data. The definitions of current (past 12 months) symptoms of wheeze, rhinoconjunctivitis and eczema and of diagnoses (ever) of asthma, hay fever and eczema were the same as reported previously. ${ }^{30}$ Additionally, the 12 -month prevalence of moderate to severe wheezing ('severe wheeze') was based on one or more of: (1) four or more attacks of wheeze, (2) woken by wheeze on one or two nights per week or (3) wheezing severe enough to limit speech to only one or two words at a time, between breaths. The prevalence of severe wheeze among those with current wheeze was estimated by the proportion of the corresponding numbers of children in each of these symptom groups. 'Atopy' was defined as rhinoconjunctivitis and/or eczema.

Various sources of data on community exposure to particulate matter were explored, including the $\mathrm{WHO}$, national electronic databases and information from the ISAAC centre investigators, but these were insufficient for our purpose because they were available for only a minority of centres and when available were not presented consistently. We therefore used the World Bank Global Model of Ambient Particulates (GMAPS) which had estimated for 1999 the annual exposure to particulate matter in residential areas of cities with populations greater than 100000 , details of which are published elsewhere $e^{28}$ and may also be found in online data supplement 1 . This is a reduced form of a fixed effect model developed using available particulate matter measurements from population based monitoring stations world-wide for 1985-1999. There were 572 locations in 304 cities in 55 countries, but these were heavily biased towards developed countries. The determinants in the model included factors such as fuel use and mix, scale and composition of economic activity, strength of local pollution regulation, and geographical and atmospheric conditions that affect pollutant transport. The model included a country-specific fixed effect to control for economic, social and natural factors not captured by the other explanatory variables. Model estimates for countries with no monitoring stations are based on an estimate of country-specific fixed effect from a secondary model. The model explained $88 \%$ of the observed variation in monitored particulate matter data in the 55 countries during the 1985-1999 period. The model used in our analysis was GMAPS 46, which estimated residential PM 10 levels for 1999.

Previous work with ISAAC Phase One has shown a weak positive association between gross national product (GNP) per capita and asthma symptoms. ${ }^{31}$ For this reason, we decided to control our analyses at a country level for GNP per capita in $1993 .{ }^{32}$

Centres were selected if there was a GMAPS estimate for annual average $\mathrm{PM}_{10}$ for their city. Where there was more than one centre per city (five cities), we selected one centre at random, to avoid overweighting that city estimate. The number of centres and some of the sample sizes differ in detail from the original Phase One reports ${ }^{27}$ because we included some centres that were too late for inclusion in the first report. The associations between $\mathrm{PM}_{10}$ and the various outcomes were estimated using a binomial logistic regression model which adjusted for GNP per capita and allowed for clustering by country according to the Huber-White estimates of variance.

For 24 countries with ISAAC centres in two or more cities, the within-country association with $\mathrm{PM}_{10}$ was estimated by fitting a separate binomial logistic regression for each country (without adjustment for GNP per capita). The country-level results for $\mathrm{PM}_{10}$ were subsequently combined using random effects metaanalysis to obtain a combined estimate.

The proportion of variability between studies attributed to heterogeneity rather than chance was estimated from $\mathrm{I}^{2}$ values. Statistical analyses were performed using STATA. ${ }^{33}$ 
Table 1 Quartile distribution of outcomes, $\mathrm{PM}_{10}$ and GNP per capita in the 6-7- and 13-14-year age groups

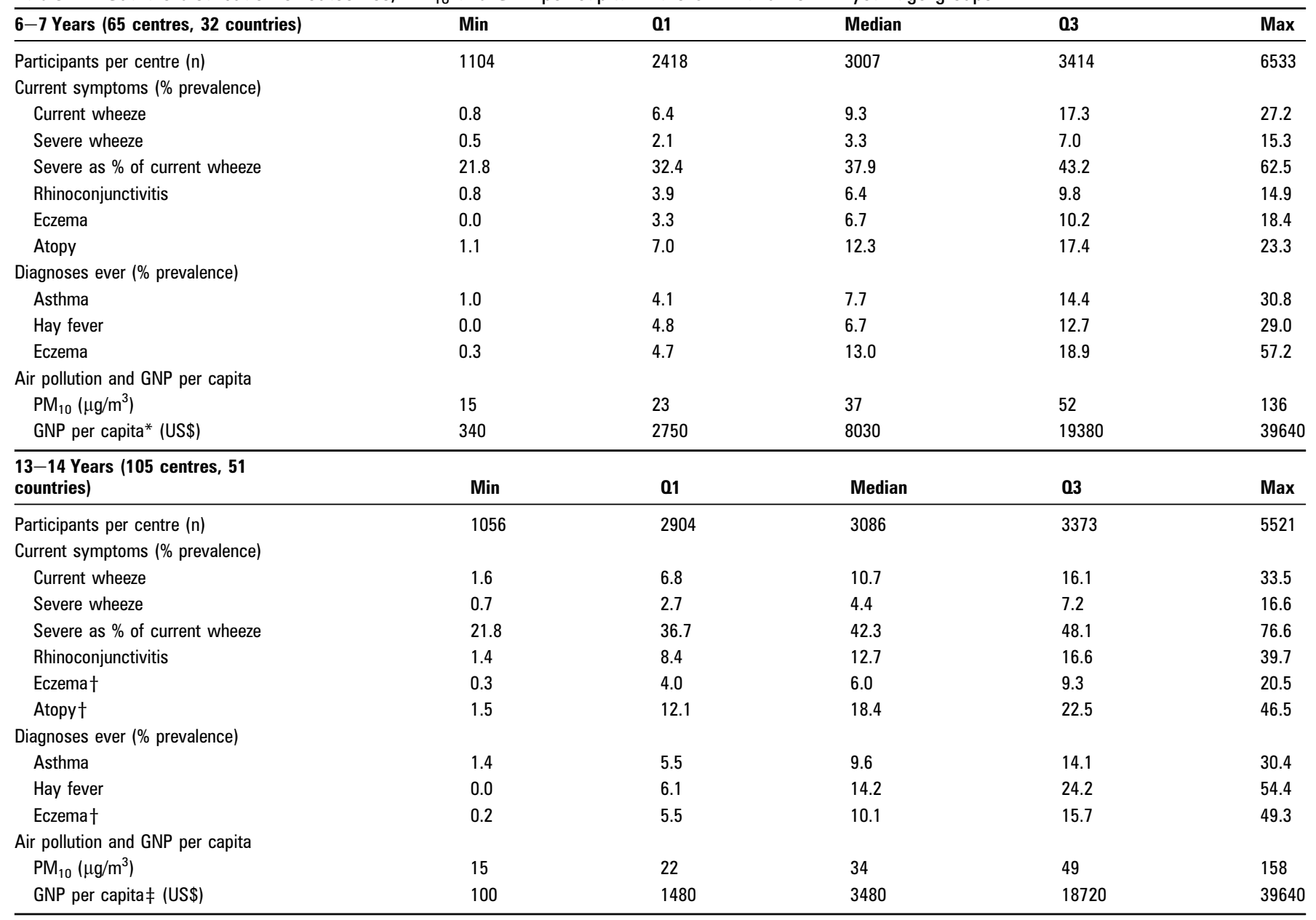

*GNP per capita estimates were based on available data for 31 countries.

†Data were available for 104 centres.

¥GNP per capita estimates are based on available data for 50 countries.

GNP, gross national product; max, maximum; min, minimum.

\section{RESULTS}

The prevalence, $\mathrm{PM}_{10}$ and GNP data for each centre in a city with an estimate for $\mathrm{PM}_{10}$ are summarised as quartiles in table 1. The individual data for each centre are given in online data supplement 2 .

For the 6-7-year age group, $\mathrm{PM}_{10}$ estimates were obtained for 65 centres in 32 countries. The median annual $\mathrm{PM}_{10}$ concentration was $37 \mu \mathrm{g} / \mathrm{m}^{3}$ (range 15-136). The median number of participants per centre was 3007 (range 1104-6533) and the total number of participants was 190624 . For the 13-14-year age group, annual $\mathrm{PM}_{10}$ estimates were obtained from 105 centres in 51 countries. The median annual $\mathrm{PM}_{10}$ concentration was $34 \mu \mathrm{g} / \mathrm{m}^{3}$ (range 15-158). The median number of participants per centre was 3086 (range 1056-5521) and the total number of participants was 322529.

For the 6-7- and 13-14-year age groups, the respective median per capita GNP was US\$8030 (range 340-39640) and US\$3480 (range 100-39640). The low GNP countries showed a wide range of $\mathrm{PM}_{10}$ levels and contained all of the high $\mathrm{PM}_{10}$ concentrations, while high GNP countries tended to have levels only in the lower range (below $50 \mu \mathrm{g} / \mathrm{m}^{3}$ ) (figure 1). A rank correlation test found a strong inverse relationship between GNP and $\mathrm{PM}_{10}$ (Spearman rho=-0.62).

Figure 2 shows the relationship between severe wheeze and $\mathrm{PM}_{10}$ for the 6-7- and 13-14-year age groups. There was a moderate to weak negative association (Spearman rho $=-0.4$ ) in both groups. The results of the logistic regression analysis adjusting for GNP per capita and clustering within country are shown in table 2 .

In both age groups, for all outcomes studied, the ORs for a $10 \mu \mathrm{g} / \mathrm{m}^{3}$ increase in $\mathrm{PM}_{10}$ concentrations remained below unity, with the exception of severe wheeze among those with current wheeze in the 13-14-year age group. The upper confidence limit for the OR was also below unity for severe wheeze and atopy in the 6-7-year age group and for current wheeze in the 13-14-year age group.

Table 3 shows the results of the meta-analysis of withincountry relationships where there was more than one centre per country.

Most of the outcomes, including those measuring wheeze and severe wheeze, showed positive summary estimates, but most had lower $95 \%$ confidence limits below unity. Three of the four estimates for which the confidence limit did not include unity were positive (hay fever in the 6-7-year age group, and rhinoconjunctivitis and atopy in the 13-14-year age group) and one was negative (asthma diagnosis in the 13-14-year age group). A more detailed description of one of these meta-analyses, that for severe wheeze in the 13-14-year age group, is shown in figure 3 which shows the ORs for the individual countries. The individual country estimates varied in size and direction, but the 


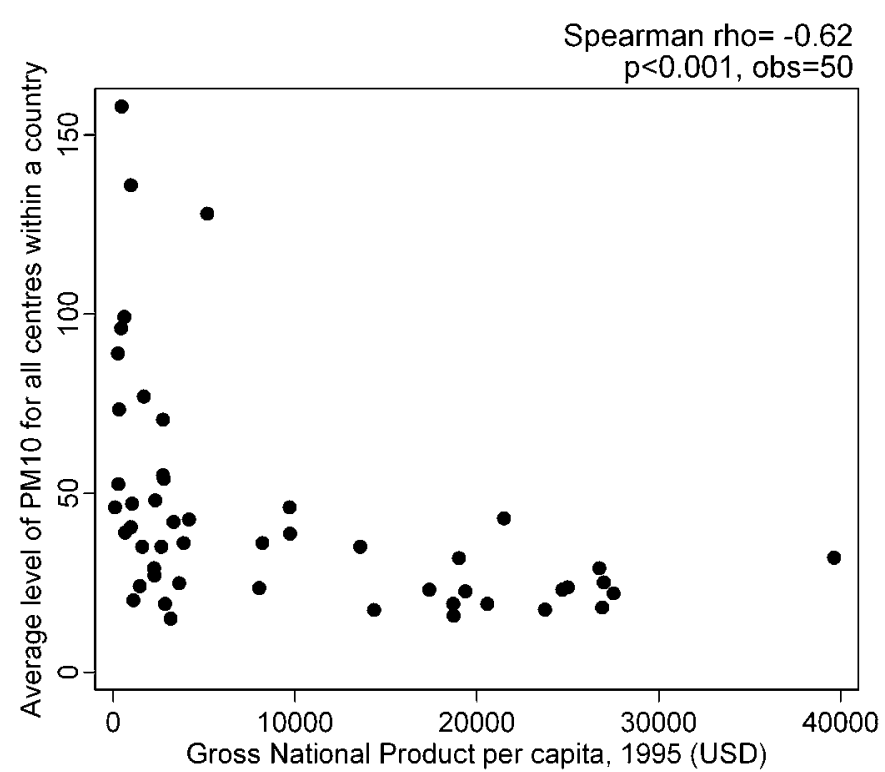

Figure 1 Correlation between $\mathrm{PM}_{10}$ (average for all centres within a country) and gross national product per capita.

overall random effects summary estimate was very close to zero. Results were similar when stratified by European versus nonEuropean and by higher versus lower GNP per capita. Each subgroup is shown ranked by annual average concentration of pollution and it is clear that neither the size nor the direction of the estimates was related to the mean level of $\mathrm{PM}_{10}$.

For both age groups, the results for severe wheeze in ISAAC countries with more than one centre were compared to the results from a meta-analysis of published multi-city studies (mostly within one country or region). This is shown in figure 4. None of the individual published studies found a significant association between wheeze symptom and $\mathrm{PM}_{10}$. There was little heterogeneity and the overall estimate without the present study was, for a 10 unit increase in $\mathrm{PM}_{10}, 0.99$ (95\% CI 0.91 to 1.06).

\section{DISCUSSION}

We generally found a weak negative relationship between concentrations of modelled residential $\mathrm{PM}_{10}$ at city level and the centre prevalence of wheeze which persisted after controlling for GNP per capita and allowing for clustering within country. A meta-analysis of within-country associations in those countries with more than one centre found mainly null associations with respect to the various symptoms with the exception of positive associations with hay fever in the 6-7-year age group and rhinoconjunctivitis and atopy in the 13-14-year age group. The results for severe wheeze were similar for European and nonEuropean centres and not related to the mean level of $\mathrm{PM}_{10}$.

The study design was ecological, with the centre as the unit of analysis. This is appropriate for a study of ambient air pollution because the exposure measurement is at an ecological level. Measurement of chronic exposure at a personal level for a multicentre prevalence study is impractical. Although many previous studies used an ecological design, most had insufficient power due to the small number of communities compared. Our study is by far the largest in terms of breadth of exposure and outcome variables, numbers of units of analysis and precision of centre prevalence estimates. In ecological analyses, it is possible to have relationships at a between-country level that are different from
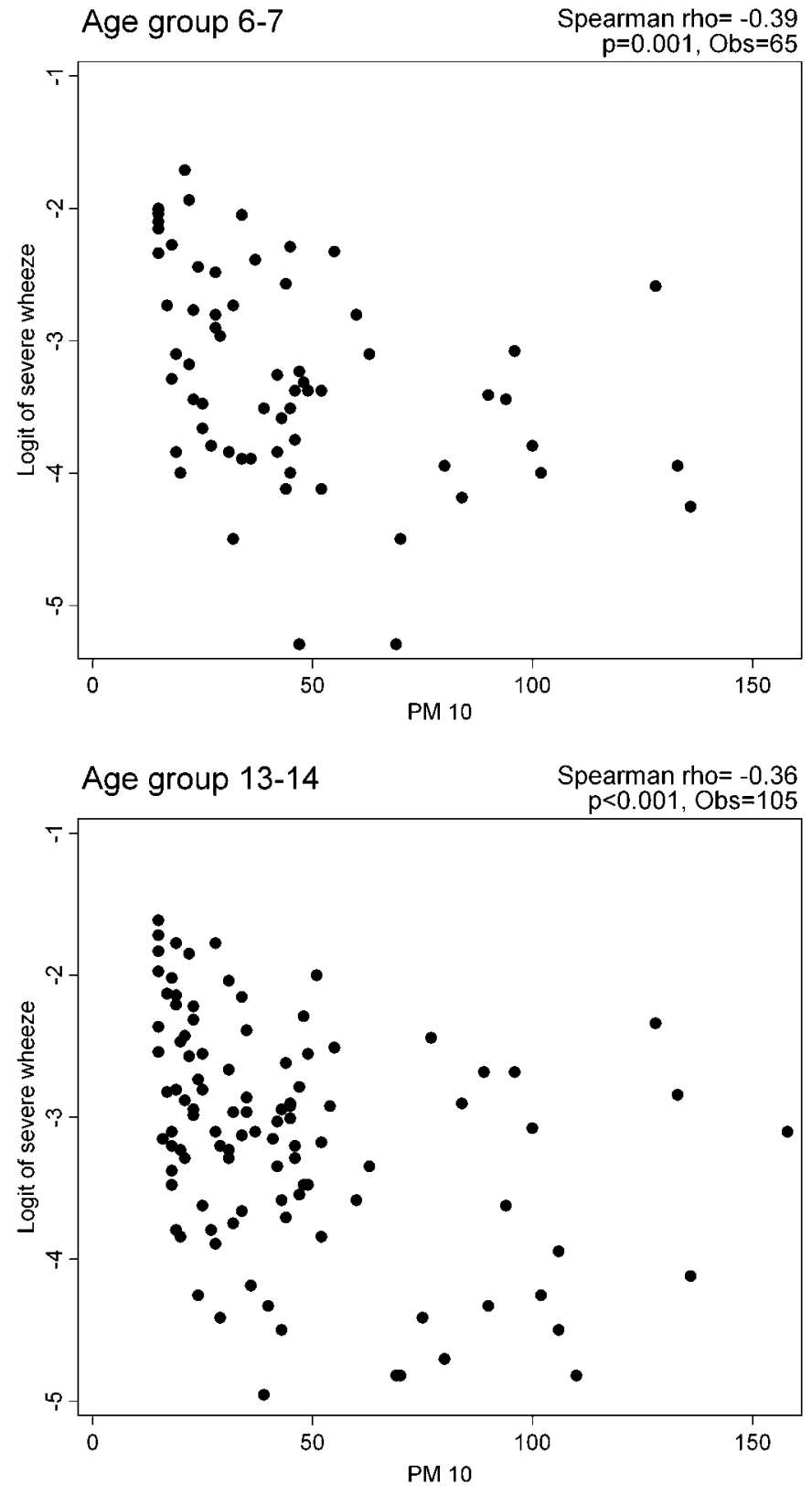

Figure 2 Association between $\mathrm{PM}_{10}$ and the prevalence of severe wheeze in 6-7- and 13-14-year-old children.

those between areas of the same country. We found that for severe wheeze, the between-country analysis (allowing for clustering of centres within country) showed a generally convincing negative association, whereas for the within-country analysis the summary estimates were more generally null. We do not know what explains this difference, but neither result supports a positive association between city-level $\mathrm{PM}_{10}$ concentrations and the various outcomes studied.

Our outcome was based on a standardised validated questionnaire and the asthma symptoms have been shown to correlate with national hospital admissions and mortality rates for childhood asthma. ${ }^{34}$ Further, prevalence estimates were obtained independently from the parents of 6-7-year-olds and from the 13-14-year-olds themselves. The sample size of each centre was large enough to ensure sufficient precision of the prevalence estimates. 
Table 2 ORs for the association between $\mathrm{PM}_{10}$ and prevalence at centre level, adjusted for GNP per capita and allowing for clustering within country

\begin{tabular}{|c|c|c|}
\hline \multicolumn{3}{|c|}{ 6-7-Year age group (63 centres, 31 countries) } \\
\hline Outcome & $\mathrm{PM}_{10}$ OR $\left(\right.$ per $\left.10 \mu \mathrm{g} / \mathrm{m}^{3}\right)$ & $95 \% \mathrm{Cl}$ \\
\hline \multicolumn{3}{|l|}{ Current symptoms (\% prevalence) } \\
\hline Current wheeze & 0.89 & 0.80 to 1.00 \\
\hline Severe wheeze & 0.88 & 0.77 to $1.00^{*}$ \\
\hline Severe as $\%$ of current wheeze & 0.97 & 0.94 to 1.00 \\
\hline Rhinoconjunctivitis & 0.93 & 0.87 to 1.00 \\
\hline Eczema & 0.92 & 0.83 to 1.02 \\
\hline Atopy & 0.93 & 0.86 to $1.00 \dagger$ \\
\hline \multicolumn{3}{|l|}{ Diagnoses ever (\% prevalence) } \\
\hline Asthma & 0.88 & 0.76 to 1.02 \\
\hline Hay fever & 0.97 & 0.86 to 1.10 \\
\hline Eczema & 0.95 & 0.85 to 1.06 \\
\hline \multicolumn{3}{|c|}{ 13-14-Year age group (103 centres, 50 countries) } \\
\hline Outcome & $\mathrm{PM}_{10}$ OR $\left(\right.$ per $\left.10 \mu \mathrm{g} / \mathrm{m}^{3}\right)$ & $95 \% \mathrm{Cl}$ \\
\hline \multicolumn{3}{|l|}{ Current symptoms (\% prevalence) } \\
\hline Current wheeze & 0.91 & 0.84 to 0.99 \\
\hline Severe wheeze & 0.92 & 0.84 to 1.00 \\
\hline Severe as $\%$ of current wheeze & 1.00 & 0.97 to 1.03 \\
\hline Rhinoconjunctivitis & 0.98 & 0.92 to 1.04 \\
\hline Eczema & 0.93 & 0.87 to 1.01 \\
\hline Atopy $\ddagger$ & 0.96 & 0.90 to 1.02 \\
\hline \multicolumn{3}{|l|}{ Diagnoses ever (\% prevalence) } \\
\hline Asthma & 0.94 & 0.87 to 1.01 \\
\hline Hay fever & 0.92 & 0.83 to 1.01 \\
\hline Eczema & 0.99 & 0.92 to 1.06 \\
\hline
\end{tabular}

In using estimates from the GMAPS model, we were able to include a far wider range of cities than would have been otherwise possible. In development, the model explained $88 \%$ of the $\mathrm{PM}_{10}$ concentrations observed in the mainly developed cities for which monitor data were available, but we do not know how well it predicted $\mathrm{PM}_{10}$ in regions that were not well represented in the development of the model (Middle East, Africa, Asia). GMAPS model estimates of annual average $\mathrm{PM}_{10}$ have recently been available for 1990-2005. PM 10 estimates for 1995 and 1999 are highly correlated $(r=0.98)$ and use of the estimates for 1999 is not expected to alter any of the findings reported in this paper. Based on a few actual measurements in cities with ISAAC centres, we found that there had tended to be a decline in $\mathrm{PM}_{10}$ from the mid-1990s to 1999, the year of the modelled concentrations and that this was steeper in the more polluted cities. This means that the concentrations in more polluted cities in 1995 will probably have been underestimated by the 1999 GMAPS model.

It is inevitable that annual average $\mathrm{PM}_{10}$ concentrations for a city will be a poor indicator of individual exposure and dose to the lung. This raises the possibility that measurement error may be obscuring a real underlying effect. However, exposure estimated at the community level is likely to have Berkson-type error rather than classical measurement error, so that effect estimates, although less precise, will not be biased towards the null. ${ }^{35}$ There are also two strands of empirical evidence which support our use of community-average concentrations of particulate matter. The first is that similar ecological study designs have found positive associations with cough symptom and reduced lung function in children. ${ }^{11}$ The second is that citylevel concentrations of particulate matter have been associated
Table 3 Meta-analysis of $\mathrm{PM}_{10}$ and prevalence in countries with more than one centre*

\begin{tabular}{|c|c|c|}
\hline \multicolumn{3}{|c|}{ 6-7-Year age group (46 centres, 14 countries) } \\
\hline Outcome & $\mathrm{PM}_{10}$ OR $\left(\right.$ per $\left.10 \mu \mathrm{g} / \mathrm{m}^{3}\right)$ & $95 \% \mathrm{CI}$ \\
\hline \multicolumn{3}{|l|}{ Current symptoms (\% prevalence) } \\
\hline Current wheeze & 1.03 & 0.95 to 1.13 \\
\hline Severe wheeze & 1.00 & 0.90 to 1.11 \\
\hline Severe as $\%$ of current wheeze & 0.97 & 0.92 to 1.01 \\
\hline Rhinoconjunctivitis & 1.06 & 0.96 to 1.17 \\
\hline Eczema & 0.98 & 0.91 to 1.05 \\
\hline Atopy & 1.03 & 0.96 to 1.10 \\
\hline \multicolumn{3}{|l|}{ Diagnoses ever (\% prevalence) } \\
\hline Asthma & 0.96 & 0.85 to 1.08 \\
\hline Hay fever & 1.10 & 1.01 to 1.19 \\
\hline Eczema & 0.97 & 0.87 to 1.08 \\
\hline \multicolumn{3}{|c|}{ 13-14-Year age group (77 centres, 24 countries) } \\
\hline Outcome & $\mathrm{PM}_{10}$ OR $\left(\right.$ per $\left.10 \mu \mathrm{g} / \mathrm{m}^{3}\right)$ & $95 \% \mathrm{CI}$ \\
\hline \multicolumn{3}{|l|}{ Current symptoms (\% prevalence) } \\
\hline Current wheeze & 1.05 & 0.97 to 1.13 \\
\hline Severe wheeze & 1.01 & 0.92 to 1.10 \\
\hline Severe as $\%$ of current wheeze & 0.97 & 0.92 to 1.02 \\
\hline Rhinoconjunctivitis & 1.15 & 1.06 to 1.26 \\
\hline Eczema† & 1.09 & 0.99 to 1.19 \\
\hline Atopy $\dagger$ & 1.14 & 1.05 to 1.24 \\
\hline \multicolumn{3}{|l|}{ Diagnoses ever (\% prevalence) } \\
\hline Asthma & 0.88 & 0.80 to 0.96 \\
\hline Hay fever & 0.98 & 0.90 to 1.07 \\
\hline Eczema† & 0.98 & 0.90 to 1.06 \\
\hline
\end{tabular}

All results are from random effects analysis.

*Estimate for Portugal excludes Funchal (Madeira island).

†Estimates are based on 75 centres, 23 countries.

with mortality in multi-city cohort studies and with a wide range of health outcomes in daily time-series studies. Therefore, in spite of many issues concerning the measurement of particulate matter, we think that if an important association with symptom prevalence had been present, we would have observed some positive relationships. We did not have the opportunity to investigate associations with pollutant gases, but the current evidence from multi-city studies cited earlier does not suggest that city-average concentrations of ozone, sulphur dioxide or nitrogen dioxide are related to community asthma prevalence.

Climate factors such as temperature, humidity and rainfall have been found to have some effect on the prevalence of asthma, eczema and hay fever in previous analyses of these ISAAC data. ${ }^{36}$ The mechanisms are not understood and it was unclear to us whether temperature should be included as a potential confounder. We also noted that climate variables were included in the GMAPS $\mathrm{PM}_{10}$ model. We investigated the association between $\mathrm{PM}_{10}$ and the same climate variables as used in the study by Weiland and colleagues and found that there was no correlation within country between $\mathrm{PM}_{10}$ and any climate variable. When we investigated the between-countries correlations, there were few significant correlations and these were weak. We therefore concluded that the particulate matter results would be unlikely to be explained by climate factors.

GNP, which was available at country level, was negatively associated with $\mathrm{PM}_{10}$ (figure 1) and positively associated with symptom prevalence in ISAAC. ${ }^{31}$ Because the estimation of $\mathrm{PM}_{10}$ used GNP per capita as an explanatory variable, we performed the between-country analysis both with and without adjustment for GNP. In both cases, the relationship between the different outcomes and $\mathrm{PM}_{10}$ was negative, although not generally significant after controlling for GNP. 
Figure 3 Meta-analysis of the association between $\mathrm{PM}_{10}$ and the prevalence of severe wheeze in the 13-14-year-age group for countries with more than one centre. Stratified by region and ranked by mean concentration of $\mathrm{PM}_{10}$. ORs for $10 \mu \mathrm{g} /$ $\mathrm{m}^{3} \mathrm{PM}_{10}$.

\begin{tabular}{|c|c|c|c|c|c|}
\hline Country & $\begin{array}{l}\text { No. of } \\
\text { centres }\end{array}$ & $\begin{array}{l}\text { PM } 10 \\
\text { average }\end{array}$ & & Odds Ratio (95\% Cl) & $\begin{array}{l}\% \\
\text { Weight }\end{array}$ \\
\hline \multicolumn{6}{|c|}{ EUROPEAN COUNTRIES } \\
\hline Sweden & 2 & 17.5 & $\longrightarrow$ & $3.19(1.49,6.83)$ & 1.16 \\
\hline Finland & 2 & 19.0 & $\longrightarrow$ & $23.52(7.79,71.03)$ & 0.61 \\
\hline France & 3 & 23.7 & & $0.71(0.62,0.80)$ & 5.79 \\
\hline Italy & 7 & 31.9 & $\bullet$ & $1.20(1.10,1.30)$ & 6.20 \\
\hline Spain & 8 & 35.0 & & $0.82(0.74,0.90)$ & 6.05 \\
\hline Portugal & 2 & 35.5 & & $0.73(0.61,0.88)$ & 5.14 \\
\hline Poland & 2 & 54.0 & & $0.91(0.71,1.17)$ & 4.39 \\
\hline Georgia & 2 & 96.0 & - & $1.06(0.75,1.49)$ & 3.36 \\
\hline \multicolumn{3}{|c|}{ Subtotal (1-squared $=93.6 \%, p=0.000)$} & & $1.09(0.85,1.41)$ & 32.69 \\
\hline \multicolumn{6}{|c|}{ NON-EUROPEAN HIGHER INCOME COUNTRIES } \\
\hline Australia & 4 & $\rightarrow$ & & $0.41(0.27,0.64)$ & 2.67 \\
\hline New Zealand & 3 & 17.3 & & $0.96(0.81,1.14)$ & 5.30 \\
\hline Canada & 2 & 22.5 & $\rightarrow$ & $1.38(1.17,1.62)$ & 5.42 \\
\hline U.S.A. & 2 & 25.0 & & $1.09(0.92,1.30)$ & 5.26 \\
\hline \multicolumn{3}{|c|}{ Subtotal (1-squared $=90.0 \%, p=0.000)$} & & $0.93(0.68,1.28)$ & 18.66 \\
\hline \multicolumn{6}{|c|}{ NON-EUROPEAN LOWER INCOME COUNTRIES } \\
\hline Morocco & 3 & 20.0 & $\longrightarrow$ & $3.89(1.73,8.78)$ & 1.04 \\
\hline Argentina & 2 & 23.5 & $\longrightarrow$ & $12.08(1.28,114.01)$ & 0.16 \\
\hline Brazil & 5 & 24.8 & & $0.89(0.84,0.95)$ & 6.36 \\
\hline Malaysia & 2 & 36.0 & & $0.82(0.75,0.91)$ & 6.11 \\
\hline Uzbekistan & 2 & 40.5 & $>$ & $1.2 e+05(2254.72,6.4 e+06)$ & 0.05 \\
\hline Chile & 3 & 42.7 & h & $1.08(1.00,1.17)$ & 6.26 \\
\hline Ethiopia & 2 & 46.0 & - & $25.75(13.89,47.74)$ & 1.62 \\
\hline Kenya & 2 & $\longrightarrow$ & & $0.05(0.02,0.09)$ & 1.51 \\
\hline Thailand & 2 & 70.5 & & $1.04(1.01,1.08)$ & 6.47 \\
\hline Iran & 2 & 71.0 & & $0.99(0.96,1.03)$ & 6.48 \\
\hline India & 9 & 73.3 & & $0.97(0.95,1.00)$ & 6.51 \\
\hline China & 4 & 99.3 & & $1.01(0.91,1.11)$ & 6.06 \\
\hline \multicolumn{3}{|c|}{ Subtotal (1-squared $=96.1 \%, p=0.000)$} & p & $1.03(0.91,1.16)$ & 48.65 \\
\hline \multirow{2}{*}{\multicolumn{3}{|c|}{$\begin{array}{l}\text { Overall (l-squared }=94.6 \%, p=0.000 \text { ) } \\
\text { NOTE: } \text { Weights are from random effects analysis }\end{array}$}} & D & $1.01(0.92,1.10)$ & 100.00 \\
\hline & & & & & \\
\hline & & $\int_{02}^{1} \int_{05}^{1}$ & $T_{20}^{1}$ & & \\
\hline
\end{tabular}

We had little scope for controlling for confounders at the individual level. Age and sex were controlled for by design but the range of individual level confounders customarily controlled for in prevalence studies (eg, active and passive smoking, other sources of indoor pollution, dampness, etc) were unavailable. ISAAC Phase Three, which was conducted during 2001-2002, included a risk factor questionnaire and future analyses using this later dataset will have the potential to adjust for some confounders at an individual level. Notwithstanding these limitations, we think that it is unlikely that any real and substantial underlying causal association between $\mathrm{PM}_{10}$ and the various outcomes has been obscured by unknown confounding factors.
Our results were very similar to those found in published studies of $\mathrm{PM}_{10}$ and the prevalence of current asthma symptoms with five or more study areas 1920222425 (figure 4). Four multiarea studies that could not be adapted for the meta-analysis of ORs (because the results could not be converted to standardised ORs) also reported essentially null results for $\mathrm{PM}_{10}{ }^{23}$ or black smoke. ${ }^{17} 1821$ The present study, also shown on figure 4, was in line with these results and the summary estimate for all multicentre studies is convincingly null. Unlike the present study which used modelled data, all of these studies used measured concentrations of $\mathrm{PM}_{10}$ or black smoke, and in some cases employed study-directed monitors. Furthermore, most of these
Figure 4 Meta-analysis of published multi-centre studies of $\mathrm{PM}_{10}$ and the prevalence of moderate to severe wheezing. ORs for $10 \mu \mathrm{g} / \mathrm{m}^{3} \mathrm{PM}_{10}$.

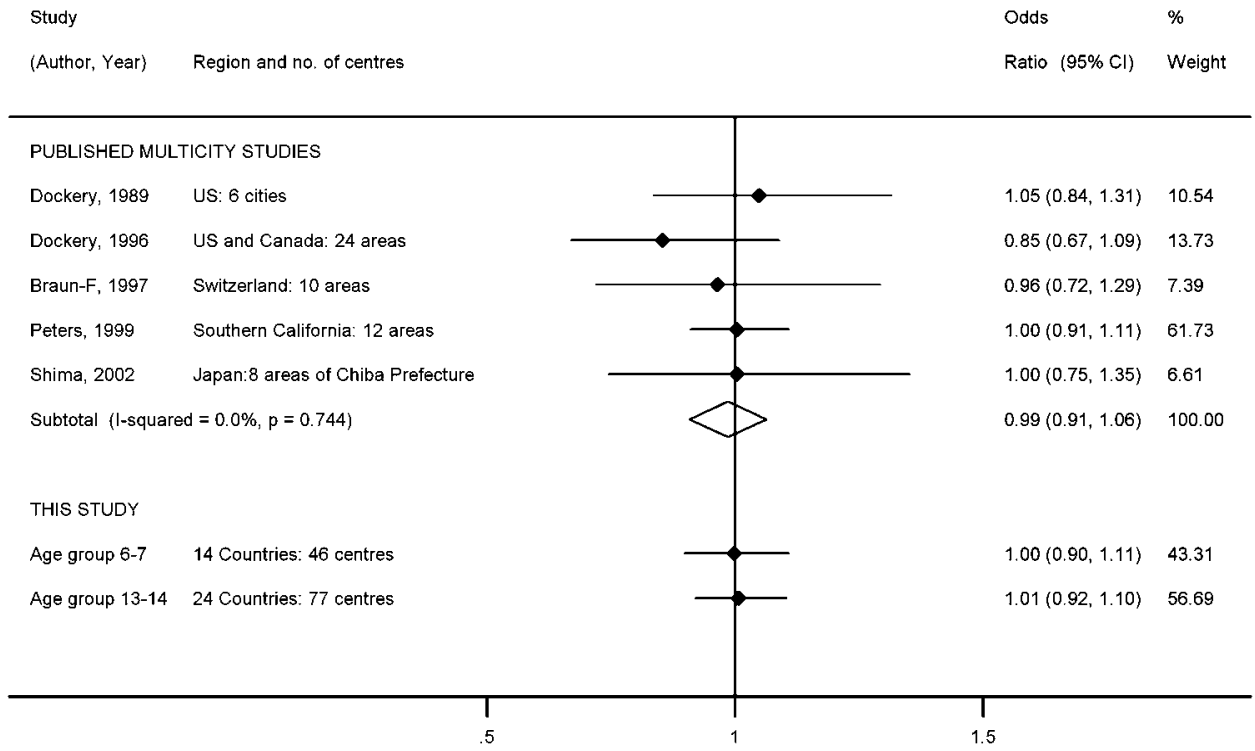


studies controlled for a range of individual-level confounding factors. The majority observed associations between $\mathrm{PM}_{10}$ and bronchitic symptoms such as cough, suggesting that they might have been capable of detecting associations with wheeze symptom should these have existed. Unfortunately, the ISAAC asthma questionnaire did not include questions on cough.

There is some evidence from within-city studies that the prevalence of asthma symptoms and of allergy may be higher in populations who are exposed to traffic than in those less exposed. ${ }^{10}$ This could be explained by fresh traffic exhaust being more toxic ${ }^{37}$ or by exposure being much higher. There is therefore a need to reconcile this evidence with that of the present study. One explanation may be that traffic pollution becomes less toxic with time and distance from the road, another is that concentrations of traffic pollution become too low and diluted with other sources for a health signal to be detected using prevalence studies such as ours. Yet another is that the contribution of traffic to the high background levels found in low GNP countries is likely to be relatively small because there is far less motorised traffic and far more uncontrolled emissions from home heating, industry, energy production, etc. An alternative explanation is that the associations observed in traffic-proximity studies are not due to pollution but to some other factor. In more recent years, better city-level data on sources have become available and we plan further studies using the ISAAC Phase Three data to investigate whether some sources are more relevant than others.

The strengths of this study lie in its world-wide scope, large sample size and standardised outcome instrument, but we recognise its relative weaknesses in exposure assessment and inability to control for confounding factors at the city and individual level. It may be possible to address some of these defects in future studies using the ISAAC data. For the present, however, we conclude that our results do not support the existence of an association between city-level concentrations of residential ambient $\mathrm{PM}_{10}$ and the prevalences of asthma, rhinoconjunctivitis or eczema.

Acknowledgements We are grateful to the children and parents who willingly cooperated and participated in ISAAC Phase One and the coordination and assistance by the school staff is sincerely appreciated. We thank the Phase One National Coordinators, Principal Investigators and their colleagues, who helped make ISAAC Phase Three such a success. We would like to acknowledge and thank the many funding bodies throughout the world that supported the individual ISAAC centres and collaborators and their meetings. In particular, we wish to thank the New Zealand funding bodies, the Health Research Council of New Zealand, the Asthma and Respiratory Foundation of New Zealand, the Child Health Research Foundation, the Hawke's Bay Medical Research Foundation, the Waikato Medical Research Foundation, Glaxo Wellcome New Zealand, the NZ Lottery Board and Astra Zeneca New Zealand. Glaxo Wellcome International Medical Affairs supported the Regional Coordination and the ISAAC International Data Centre. Without help from all of the above, ISAAC would not have given us all these results from so many countries.

\section{Competing interests None}

Ethics approval Each collaborator (appendix 1) obtained ethical approval for their respective centre or centres.

Provenance and peer review Not commissioned; externally peer reviewed.

\section{REFERENCES}

1. Global Strategy for Asthma Management and Prevention, Global Initiative for Asthma (GINA) 2007. http://www.ginasthma.org (accessed Mar 2008).

2. ISAAC Steering Committee. Worldwide variations in the prevalence of asthma symptoms: the International Study of Asthma and Allergies in Childhood (ISAAC). Eur Respir J 1998;12:315-35.

3. Pearce N, Ait-Khaled N, Beasley R, et al. Worldwide trends in the prevalence of asthma symptoms: phase III of the International Study of Asthma and Allergies in Childhood (ISAAC). Thorax 2007:62:758-66.

4. Pope CA III, Dockery DW. Health effects of fine particulate air pollution: lines that connect. J Air Waste Manag Assoc 2006;56:709-42.
5. World Health Organization Regional Office for Europe 2007, Health relevance of particulate matter from various sources: report on a WHO workshop, Bonn, Germany, March 2007 WHO, Copenhagen.

6. Brunekreef B, Holgate ST. Air pollution and health. Lancet 2002;360:1233-42.

7. Riedl M, Diaz-Sanchez D. Biology of diesel exhaust effects on respiratory function. J Allergy Clin Immunol 2005;115:221-8.

8. Holgate ST, Sandstrom T, Frew AJ, et al. Health effects of acute exposure to air pollution. Part I: Healthy and asthmatic subjects exposed to diesel exhaust. Res Rep Health Eff Inst 2003;112:1-30.

9. Department of Health Committee on the Medical Effects of Air Pollutants. Asthma and outdoor air pollution. London: HMSO, 1995.

10. World Health Organisation. Air quality guidelines: global update 2005, particulate matter, ozone, nitrogen dioxide and sulphur dioxide. Copenhagen: WHO Regional Office for Europe, 2006.

11. WHO European Centre for Environment and Health. Effects of air pollution on children's health and development - a review of the evidence. Bonn: WHO Regional Office for Europe, 2005.

12. Brauer M, Hoek G, Smit HA, et al. Air pollution and development of asthma, allergy and infections in a birth cohort. Eur Respir J 2007;29:879-88.

13. Morgenstern V, Zutavern A, Cyrys J, et al. Atopic diseases, allergic sensitization, and exposure to traffic-related air pollution in children. Am J Respir Crit Care Med 2008;177:1331-7.

14. Nordling E, Berglind N, Melen E. Traffic-related air pollution and childhood respiratory symptoms, function and allergies. Epidemiology 2008;19:401-8.

15. Salam MT, Islam T, Gilliland FD. Recent evidence for adverse effects of residential proximity to traffic sources on asthma. Curr Opin Pulm Med 2008; 14:3-8.

16. Heinrich J, Wichmann HE. Traffic related pollutants in Europe and their effect on allergic disease. Curr Opin Allergy Clin Immunol 2004;4:341-8.

17. World Health Organisation. Study on chronic respiratory diseases in children in relation to air pollution. Geneva: WHO, 1980.

18. Florey CD, Swan AV, Van der Lende R, et al. Report on the EC epidemiological survey on the relationship between air pollution and respiratory health in primary schoolchildren. Brussels: Commission of the European Communities, 1983.

19. Braun-Fahrlander C, Vuille JC, Sennhauser FH, et al. Respiratory health and long-term exposure to air pollutants in Swiss schoolchildren. SCARPOL Team. Swiss Study on Childhood Allergy and Respiratory Symptoms with Respect to Air Pollution, Climate and Pollen. Am J Respir Crit Care Med 1997; 155:1042-9.

20. Dockery DW, Speizer FE, Stram DO, et al. Effects of inhalable particles on respiratory health of children. Am J Respir Crit Care Med 1989;139:587-94.

21. Baldi I, Tessier JF, Kauffmann F, et al. Prevalence of asthma and mean levels of air pollution: results from the French PAARC survey. Pollution Atomospherique et Affections Respiratoires Chroniques. Eur Respir J 1999;14:132-8.

22. Dockery DW, Cunningham J, Damokosh Al, et al. Health effects of acid aerosols on North American children: Respiratory symptoms. Environ Health Perspect 1996; 104:500-5

23. Guo YL, Lin YC, Sung FC, et al. Climate, traffic-related air pollutants and asthma prevalence in middle-school children in Taiwan. Environ Health Perspect 1999;107:1001-6.

24. Peters JM, Avol E, Navidi W, et al. A study of twelve Southern California communities with differing levels and types of air pollution. I. Prevalence of respiratory morbidity. Am J Respir Crit Care Med 1999;159:760-7.

25. Shima M, Nitta $Y$, Ando $M$, et al. Effects of air pollution on the prevalence and incidence of asthma in children. Arch Environ Health 2002;57:529-35.

26. Pattenden S, Hoek G, Braun-Fahrlander C, et al. N02 and children's respiratory symptoms in the PATY study. Occup Environ Med 2006;63:828-35.

27. ISAAC Steering Committee. Worldwide variation in prevalence of symptoms of asthma, allergic rhinoconjunctivitis, and atopic eczema: ISAAC. The International Study of Asthma and Allergies in Childhood (ISAAC) Steering Committee. Lancet 1998:351:1225-32.

28. Pandey KD, Wheeler D, Ostro B, et al. Ambient particulate matter concentrations in residential areas of world cities: new estimates based on global model of ambient pollutants (GMAPS). Washington DC: World Bank, 2003.

29. Asher MI, Keil U, Anderson HR, et al. International Study of Asthma and Allergies in Childhood (ISAAC): rationale and methods. Eur Respir J 1995;8:483-91.

30. Asher MI, Montefort S, Bjorksten B, et al. Worldwide time trends in the prevalence of symptoms of asthma, allergic rhinoconjunctivitis, and eczema in childhood: ISAAC Phases One and Three repeat multi-country cross-sectional surveys. Lancet 2006; 368:733-43.

31. Stewart AW, Mitchell EA, Pearce N, et al. The relationship of per capita gross national product to the prevalence of symptoms of asthma and other atopic diseases in children (ISAAC). Int J Epidemiol 2001;30:173-9.

32. World Bank. World Development Report. Oxford: Oxford University Press, 1995.

33. Anon. STATA/SE 9.2 Statistics/Data Analysis. College Station, TX: Stata Corporation, 2007.

34. Anderson HR, Gupta R, Kapetanakis V, et al. International correlations between indicators of prevalence, hospital admissions and mortality for asthma in children. Int J Epidemiol 2008;37:573-82.

35. Zeger SL, Thomas D, Dominici F, et al. Exposure measurement error in time-series studies of air pollution: concepts and consequences. Environ Health Perspect 2000; 108:419-26. 
36. Weiland SK, Husing A, Strachan DP, et al. Climate and the prevalence of asthma, allergic rhinitis and atopic eczema in children. Occup Environ Med 2004;61:609-15.

37. McCreanor J, Cullinan P, Nieuwenhuijsen MJ, et al. Respiratory effects of exposure to diesel traffic in persons with asthma. N Engl J Med 2007;357:2348-58.

\section{APPENDIX 1: ISAAC PHASE ONE STUDY GROUP}

ISAAC Steering Committee: N Ait-Khaled (Union Internationale Contre la Tuberculose et les Maladies Respiratoires, Paris, France); G Anabwani (Princess Marina Hospital, Gaborone, Botswana); HR Anderson (Department of Public Health Sciences, St George's Hospital Medical School, London, UK); MI Asher (Department of Paediatrics, Faculty of Medical and Health Sciences, The University of Auckland, New Zealand); R Beasley (Medical Research Institute of New Zealand, Wellington, New Zealand): B Björkstén (Institute of Environmental Medicine, Karolinska Institutet, Stockholm, Sweden); ML Burr (Department of Epidemiology, Statistics and Public Health, University of Wales College of Medicine, Cardiff, UK); J Crane (Wellington Asthma Research Group, Wellington School of Medicine, New Zealand); U Keil (Institut für Epidemiologie und Sozialmedizin, Universität Münster, Germany); CKW Lai (Department of Medicine and Therapeutics, The Chinese University of Hong Kong, SAR China); J Mallol (Department of Respiratory Medicine, University of Santiago de Chile, Chile); FC Martinez (Arizona Respiratory Center, University of Arizona, Tucson, Arizona, USA); EA Mitchell (Department of Paediatrics, Faculty of Medical and Health Sciences, The University of Auckland, New Zealand); S Montefort (Department of Medicine, University of Malta, Malta); N Pearce (Centre for Public Health Research, Massey University, Wellington, New Zealand); CF Robertson (Department of Respiratory Medicine, Royal Children's Hospital, Parkville, Australia); JR Shah (Jaslok Hospital \& Research Centre, Mumbai, India): AW Stewart (Population Health, Faculty of Medical and Health Sciences, The University of Auckland, New Zealand); DP Strachan (Department of Public Health Sciences, St George's Hospital Medical School, London, UK); E von Mutius (Dr von Haunerschen Kinderklinik de Universität München, Germany); SK Weiland (Department of Epidemiology, University of Ulm, Germany); HC Williams (Centre for Evidence Based Dermatology, Queen's Medical Centre, University Hospital, Nottingham, UK).

ISAAC International Data Centre: MI Asher, TO Clayton, P Ellwood, EA Mitchell, Department of Paediatrics, and AW Stewart, School of Population Health, Faculty of Medical and Health Sciences, The University of Auckland, New Zealand.

ISAAC Phase One principal investigators: Algeria: Dr A Bezzaoucha (Algiers); Ethiopia: Associate Professor K Melaku (Addis Ababa); Ethiopia: Professor B Seyoum (Jima); Kenya: Dr FO Esamai (Eldoret), Dr JA Odhiambo (Nairobi); Nigeria: Professor BO Onadeko (Ibadan): South Africa: Professor R Ehrlich (Cape Town); China: Professor Y-Z Chen (Beijing), Professor K-H Chen (Chongqing), Professor N-S Zhong (Guangzhou), Dr M Bao-Shan (Shanghai); Hong Kong: Dr C Lai (Hong Kong 13-14- year-old children), Professor Y Lung Lau (Hong Kong 6-7-year-old children): Indonesia: Professor Dr K Baratawidjaja (Bandung); Japan: Professor S Nishima (Fukuoka); Malaysia: Dr LW Yeong (Ipoh), Associate Professor BS Quah (Kota Bharu) Philippines: Professor F Cua-Lim (Metro Manilla); Republic of Korea: Dr S-I Lee (Seoul); Singapore: Professor B-W Lee (Singapore); Taiwan: Professor K-H Hsieh (deceased) (Taipei); Thailand: Dr P Vichyanond (Bangkok), Associate Professor M Trakultivakorn (Chiang Mai): Iran: Dr M-R Masjedi (Rasht and Tehran): Kuwait: Dr JA al-Momen (Kuwait); Lebanon: Dr FM Ramadan (Beirut); Morocco: Professor Z Bouayad (Casablanca and Marrakech), Professor A Bennis (Rabat); Pakistan: Dr ZA Bhutta (Karachi); Argentina: Dr N Salmun (Buenos Aires and Rosario); Brazil: Professor N Rosário (Curitiba), Professor R Stein (Porto Alegre), Dr PGM Bezerra (Recife), Associate Professor L de Freitas Souza (Salvador), Professor D Solé (Sao Paulo); Chile: Dr I Sanchez (Central Santiago), Dr L Amarales (Punta Arenas), Dr MA Calvo (Valdivia); Mexico: Professor I Romieu (Cuernavaca); Panama: Dr G Cukier (David-Panama); Paraguay: Dr JA Guggiari-Chase (Asuncion); Peru: Dr P Chiarella (Lima); Uruguay: Dra D Holgado (Montevideo); Canada: Professor M Sears (Hamilton), Dr B Taylor (Saskatoon); USA: Dr V Persky (Chicago (3)), Professor GJ Redding (Seattle); Albania: Professor A Priftanji (Tirane); Estonia: Dr M-A Riikjärv (Tallinn); Finland: Dr M Kajosaari (Helsinki), Dr TA Koivikko (Turku and Pori County); Georgia: Dr N Khetsuriani (Kutaisi), Professor A Gamkrelidze (Tbilisi); Latvia: Dr M Leja (Riga); Poland: Associate Professor G Lis (Krakow), Dr A Brêborowicz (Poznan); Roumania: Professor D Dumitrascu (Cluj); Russian Federation: Professor RM Khaitov (Moscow); Sweden: Dr L Nilsson (Linkoping), Dr T Foucard (Stockholm/Uppsala); Uzbekistan: Professor T Aripova (Samarkand and Tashkent); Australia: Dr D Kennedy (Adelaide), Professor C Robertson (Melbourne), Professor L Landau (Perth), Dr J Peat (Sydney 6-7-year-old children), Professor A Bauman (Sydney 13-14-year-old children); New Zealand: Professor Ml Asher (Auckland), Associate Professor P Pattemore (Christchurch), Professor J Crane (Wellington): India: Dr RM Maheshwari (Akola), Dr MK Joshi (Bombay (16)). Professor L Kumar (Chandigarh), Dr KC Jain (Jodhpur), Dr TU Sukumaran (Kottayam), Dr N Somu (Madras (3)). Professor GR Sethi (New Delhi (7)). Dr G Jayaraj (Neyveli). Dr NM Hanumante (Pune); Austria: Dr J Riedler (Salzburg); Belgium: Professor P Vermeire (Antwerp); France: Professor D Charpin (Marseilles), Professor P Godard (Montpellier), Dr C Kopferschmitt-Kubler (Strasbourg); Germany: Professor Dr U Keil (Munster); Greece: Associate Professor C Gratziou (Athens); Italy: Dr F Forastiere (Cosenza and Roma), Dr E Chellini (Firenze), Dr L Bisanti (Milano), Dr G Ciccone (Torino), Dr S Piffer (Trento), Professor A Boner (Verona); Portugal: Dr FD Borges (Funchal), Professor JE Rosado Pinto (Lisbon). Dr JM Lopes dos Santos (Porto): Spain: Dr RM Busquets (Barcelona), Dr AD Rubio (Bilbao), Dr AR Asensio (Cadiz), Professor L García-Marcos (Cartagena), Dr A Arnedo-Pena (Castellon), Professor F Guillén-Grima (Pamplona), Professor MMM Suárez-Varela (Valencia), Professor A Blanco Quirós (Valladolid); United Kingdom: Professor HR Anderson (South Thames). 


\section{Ambient particulate pollution and the world-wide prevalence of asthma, rhinoconjunctivitis and eczema in children: Phase One of the International Study of Asthma and Allergies in Childhood (ISAAC)}

H Ross Anderson, Ruth Ruggles, Kiran D Pandey, et al.

Occup Environ Med 2010 67: 293-300 originally published online October 9, 2009

doi: 10.1136/oem.2009.048785

Updated information and services can be found at:

http://oem.bmj.com/content/67/5/293.full.html

\section{These include:}

Data Supplement

References Email alerting
service
"Web Only Data"

http://oem.bmj.com/content/suppl/2010/05/25/oem.2009.048785.DC1.html

This article cites 27 articles, 9 of which can be accessed free at:

http://oem.bmj.com/content/67/5/293.full.html\#ref-list-1

Article cited in:

http://oem.bmj.com/content/67/5/293.full.html\#related-urls

Receive free email alerts when new articles cite this article. Sign up in the box at the top right corner of the online article.

Notes

To request permissions go to:

http://group.bmj.com/group/rights-licensing/permissions

To order reprints go to:

http://journals.bmj.com/cgi/reprintform

To subscribe to BMJ go to:

http://group.bmj.com/subscribe/ 